\title{
Human rights in the new Global Strategy
}

\section{By recognising the centrality of human rights, the revised Global Strategy encourages some bold chifts in improving the health and wellbeing of women, children, and adolescents, say Jyo@ $\bigcirc$ CrossMark}

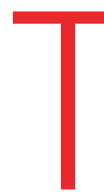

he Global Strategy for Women's and Children's Health (2010), with its emphasis on participatory decision making processes, non-discrimination, and accountability, affirmed the importance of human rights. Despite important gains following its launch women, children, and adolescents continue to experience serious violations of their health and health related human rights, including discrimination in access to quality healthcare. A human rights based approach must thus be fully integrated throughout the Global Strategy.

The right to health is recognised by several legal tools and treaties relating to human rights, including the International Covenant on Economic, Social and Cultural Rights; the Convention on the Rights of the Child; and the Convention on the Elimination of All Forms of Discrimination against Women. A human rights framework for realising the right to health of women, children, and adolescents calls for national governments to ensure that health facilities, goods, and services are of good quality, are available in sufficient quantity, and are physically accessible and affordable on the basis

\section{KEY MESSAGES}

Unless human rights are integrated throughout the Global Strategy for Women's, Children's and Adolescents' Health, the health and health related rights of these groups will not be fully realised Despite important gains women, children, and adolescents continue to experience serious violations of their health and health related human rights

Insufficient attention to discrimination and social exclusion in policy development and service provision consistently undermine efforts to ensure and improve access to and quality of care

Health is a justiciable human right that is interdependent with and indivisible from other human rights, including the rights to life, bodily integrity, autonomy, information, and privacy

Key interventions in the area of policy and legislation, equality and nondiscrimination, service delivery, stakeholder participation, the underlying determinants of health, and accountability are proposed of non-discrimination. ${ }^{1}$ Health facilities, goods, and services must also be acceptablethat is, gender and child sensitive and respectful of confidentiality and the requirement for informed consent, among other things.

A human rights based approach is based on accountability and on empowering women, children, and adolescents to claim their rights and participate in decision making, and it covers the interrelated determinants of health and wellbeing (box). Because a human rights based approach promotes holistic responses, rather than fragmented strategies, and requires attention to the health needs of marginalised and vulnerable populations, it is a valuable tool for improving health outcomes.

\section{Methods}

The methods we used in this article comprise reference to existing human rights norms documented in relevant legal texts, as interpreted by authoritative guidance and expert opinion. We drew our recommendations on the basis of the need for health laws and practices to conform to human rights standards, a need identified by common and well known trends in government policy and practice.

\section{Human rights problems}

Many of the barriers faced by women, children, and adolescents in accessing healthcare and other entitlements and services that affect their ability to live healthy lives are a consequence of the denial of human rights.

\section{Women and girls}

Laws, policies, and practices often discriminate against women and girls, resulting in the denial of autonomy and agency and in differential access to healthcare. Gender stereotypes and discrimination against women and girls often result in the perpetuation of harmful practices such as early, childhood, or forced marriage; gender based violence; female genital mutilation; neglect; and infanticide. Although laws and policies have been put in place to prevent these practices, prevailing social norms continue to play an important part in confining women to the role of mothers and caregivers and limiting access to education, paid employment, and equal opportunities.
Lack of autonomy, agency, and economic independence affects the ability of women to access health services or to interact with health systems in ways that respect their rights to privacy and confidentiality, which in turn may inhibit them from seeking these services. This is, arguably, most evident in the area of reproductive and sexual health, where maternal mortality and morbidity rates remain high. ${ }^{2}$ The health situation of the most marginalised groups of women and girls, including those belonging to sexual minorities, ethnic minorities, and rural communities and women and girls with disabilities, is especially acute in all of the above respects.

\section{Children}

States have an obligation, under human rights law, to take measures to protect the right of the child to life and to ensure his or her survival and development. ${ }^{3}$ One major challenge to reducing ill health in children is the failure to systematically identify and overcome the root causes. These include the denial of the right to adequate water, sanitation, and hygiene; malnutrition; the failure to provide safe and secure living environments; harmful practices; and discrimination. All of these have an effect on the ability to enjoy good health and to access good quality healthcare. ${ }^{4}$ In addition, young children are often victims of neglect, maltreatment, and abuse; their inability to protect themselves or to seek the protection of others renders them particularly at risk.

Respect for the status of children as rights holders and for their agency is a pre-condition for the full exercise of their health and health related rights. This is often ignored or rejected owing to conceptions about age and immaturity, as well as to cultural norms governing the child's role in the family and broader society. ${ }^{5}$ The failure to ensure that the best interests of the child are assessed and taken as a primary consideration in all actions affecting children is also implicated in poor responses to child health, ${ }^{6}$ as is the violation of the right of children to express their views and to have these views seriously taken into account, according to age and maturity. ${ }^{7}$ This is true to an even greater extent for marginalised or vulnerable groups of children, such as children with disabilities, children affected by HIV/AIDS, migrant children, children in detention, and child 
HUMAN RIGHTS ADD VALUE

To meet their obligation to respect, fulfil, and protect the right to health and other health rights guaranteed under international human rights law, governments can adopt a human rights based approach by:

- Providing access to affordable, acceptable, and good quality healthcare and services for all women, children, and adolescents on an equal footing

- Empowering women, children, and adolescents to claim their rights and participate in decision making

- Putting in place the necessary policy and legal frameworks to ensure the accountability of all actors involved in health service delivery

- Adopting comprehensive strategies, working together with other sectors that affect health, to respond to the full range of health challenges faced by women, children, and adolescents

- Engaging multiple stakeholders, including children and adolescents, in policy formulation, implementation, and review and supporting their consistent participation

- Improving health outcomes for marginalised, excluded, and vulnerable women, children, and adolescents

refugees and internally displaced people. In much the same way that early childhood development profoundly affects health throughout life, the poor realisation of rights in childhood frequently determines the enjoyment of rights in later life. ${ }^{89}$

\section{Adolescents}

Whereas maternal and child mortality and morbidity have received increasing attention, adolescent health has not benefited to the same extent despite the fact, for instance, that the highest rate of maternal deaths is among adolescent girls. ${ }^{10}$ Adolescence is an important developmental stage presenting particular challenges for health and wellbeing. From puberty, the risks associated with sexual violence, childhood and early marriage, unwanted pregnancy, maternal mortality and morbidity, and the incidence of HIV and other sexually transmitted infections increase exponentially. Proactive measures are needed to ensure that risks are averted and that these early years lay down strong foundations for a healthy life.

Adolescents face considerable barriers in accessing high quality healthcare and services, particularly sexual and reproductive health services and information, that respond to their needs and their evolving capacities. Access to sexual and reproductive health services and information is often hindered as a result of laws and regulations imposing restrictions relating to minimum age, third party authorisation, or marital status. Policies that allow health service providers to deny women sexual and reproductive health services on the basis of their religious beliefs while simultaneously failing to ensure alternative access to these services, negative and discriminatory attitudes grounded in personal beliefs regarding adolescent sexuality, and cultural norms can all be major factors preventing or inhibiting access to sexual and reproductive health services and information.

\section{Response and priority interventions}

Below we set out the priority human rights interventions to advance the health and health related rights of women, children, and adolescents. Although not exhaustive, these interventions would, if implemented, help to overcome major obstacles to the realisation of these rights and, through that, provide solutions to many of the health challenges. The web appendix expands on the interventions under each heading.

\section{Enabling policy and legal environment}

Laws and policies have a direct bearing on the realisation of health and human rights by women, children, and adolescents, so an enabling legal and policy environment is indispensable. Legislative and policy interventions should be geared towards the enactment, amendment, or repeal of laws and policies, as necessary, to align legal and policy frameworks with human rights norms. ${ }^{11} 12$ Priority interventions should be to:

\section{- Collect comprehensive data disaggregated} by sex, age, disability, race, ethnicity, mobility, or economic or other status, as nationally relevant, to identify women, children, and adolescents facing discrimination in access to healthcare and other entitlements and services that affect their health and related human rights.

- Conduct an assessment of the extent to which existing legal and policy frameworks comply with the human rights norms applicable to health and wellbeing, as part of a comprehensive analysis, through a participatory, inclusive, and transparent process, with stakeholder consultation throughout.

- Repeal, rescind, or amend laws and policies that create barriers or restrict access to health services and that discriminate, explicitly or in effect, against women, children, and adolescents as such or on grounds prohibited under human rights law. This includes the repeal of laws that criminalise specific sexual and reproductive conduct and decisions, such as abortion, same sex intimacy, and sex work.

- Enact laws and implement policies promoting positive measures to ensure that essential health services, including primary healthcare, sexual and reproductive health services, maternal health services, and neonatal, child, and adolescent health services are available, accessible, acceptable, and of good quality.

- Prohibit harmful practices such as early, forced, or childhood marriage; female genital mutilation; and violence against women, children, and adolescents, including gender based violence.

- Promote social mobilisation, education, information, and awareness raising programmes and campaigns to challenge discrimination and harmful social norms and to create legal awareness and literacy among health service personnel and beneficiaries, with a focus on women, children, and adolescents, including vulnerable and marginalised groups within these populations.

\section{Participation}

The meaningful participation of all women, children, and adolescents, including those from marginalised or vulnerable groups, in the formulation, implementation, and monitoring of policies that affect their health is an essential building block of a human rights based approach. Priority interventions should be to:

- Build the capacity of rights holders to participate and to claim their rights, through education and awareness raising, and ensure that transparent and accessible mechanisms for engaging stakeholders' participation and facilitating regular communication between rights holders and health service providers are established and/or strengthened at community, sub-national, and national levels.

- Ensure stakeholders' participation in priority setting; in policy and programme design, implementation, monitoring, and evaluation; and in accountability mechanisms. This can be achieved by establishing and/or strengthening transparent participation and social dialogue or multi-stakeholder mechanisms at community, sub-national, and national levels and ensuring that participation outcomes inform sub-national, national, and global policies and programmes related to women's, children's, and adolescents' health. ${ }^{13}$

\section{Equality and non-discrimination}

Discrimination on grounds prohibited under international human rights law, including 
on account of gender, age, race, ethnicity, income, and location, severely undermines the enjoyment of human rights. Priority interventions should be to:

\section{- Develop, fund, and implement a national strategy to eliminate discrimination against women, children, and adolescents in access to health services and in health- care, taking into account, particularly, gender and age based discrimination. \\ - Tackle the specific barriers faced by women, children, and adolescents from marginalised and vulnerable population groups-for example, through the provi- sion of culturally appropriate health ser- vices for indigenous peoples, the provision of health information in formats that are accessible to people with disabilities, and health coverage for both documented and undocumented migrant populations.}

\section{Planning and budgeting}

States have an obligation to take steps to achieve the progressive realisation of the right to health of women, children, and adolescents to the maximum of their available resources. ${ }^{1415}$ Priority should be given to securing adequate funding for the health and health related sectors and to implementing comprehensive strategies and plans of action. ${ }^{16}$ Priority interventions should be to:

- Formulate comprehensive, rights based, coordinated, multi-sectoral strategies and adequately resourced plans of action mandating action to ensure the accessibility, availability, acceptability, and quality of facilities, goods, and services, without discrimination, and to reduce barriers to access. ${ }^{1718}$ Plans of action should include targets and indicators prioritised through a participatory and inclusive process and should focus attention on the health needs of women, children, and adolescents.

- Establish participatory budget processes with a view to ensuring transparency and promoting the involvement of women, children, and adolescents in monitoring the allocation and utilisation of resources for their health. ${ }^{19}$

\section{Rights based services}

Interventions in this area are those aimed at ensuring that health facilities, goods, and services are of good quality, are available in sufficient quantity, and are physically accessible and affordable on the basis of non-discrimination. Priority interventions should be to:

- Implement comprehensive strategies, formulated through consultative processes and user participation, for ensuring access to high quality and affordable healthcare for diseases affecting women, children, and adolescents, in an environment that guarantees free and informed decision making and respect for privacy, autonomy, and agency. Health information, counselling, and education should be evidence based, in line with human rights, and readily available and accessible to women and adolescents as well as children, in accordance with their level of maturity.

- Provide for universal access to health coverage for all women, children, and adolescents, including those from marginalised or vulnerable populations and those employed in the informal sector. Coverage should identify the priority interventions guaranteed, and services should be free at the point of access to ensure the protection of privacy and confidentiality.

- Provide comprehensive training on the health rights of women, children, and adolescents; the effect of discrimination; and the importance of communication and respect for patients' dignity in healthcare settings. This should be an integral part of all training for health personnel.

\section{Structural and other determinants of health}

The right to health encompasses access both to healthcare and to other factors affecting health such as adequate nutrition, housing, water, sanitation, and hygiene. ${ }^{2021} \mathrm{~A}$ human rights based approach to women's, children's, and adolescents' health requires a multifaceted, multisectoral approach to improve the determinants of health and ensure the full realisation of the right to health and related rights. A review of the determinants of health, together with proposed interventions, is available in the article entitled "Socioeconomic, political, and environmental determinants," also published as part of this series. ${ }^{22}$

\section{Accountability}

A human rights based approach requires strong accountability mechanisms that include redress, remedial action, and guarantees of non-repetition. Effective accountability at country level involves a diverse range of actors within and beyond the health sector and requires multiple forms of review and oversight, including administrative, political, legal, and international accountability. ${ }^{23}$ Priority interventions should be to:

- Establish and/or strengthen transparent, inclusive, and participatory processes and mechanisms, with jurisdiction to recommend remedial action, for independent accountability at the national, regional, and global level within both the health and the justice systems. ${ }^{24}$ These include courts or quasi-judicial and non-judicial bodies, complaints mechanisms within the health system, national human rights institutions, and professional standards associations.

- Develop a national strategy to promote access to justice mechanisms for women, children, and adolescents. Measures include identifying and removing barriers to access, such as cost, through the provision of free legal assistance, the establishment of mobile courts or other redress mechanisms to facilitate physical access, and ensuring that services are available in languages that are understood by the client communities. ${ }^{25}$

\section{Conclusion}

Most barriers to access to healthcare facing women, children, and adolescents can, arguably, be attributed to the failure to integrate human rights into health law and policy and to tackle violations of the right to health. The Global Strategy presents a valuable opportunity to reduce deficits in implementing a human rights based approach to the health of women, children, and adolescents by mobilising national efforts to this end. The human rights interventions proposed in this paper aim to respond to the common areas in which national implementation tends to be weak and to focus attention on where the most significant gains potentially stand to be made.

The human rights sub-work stream is composed of the following members in addition to those named as authors of this paper: Janette Amer (UN Women), Francesco Aureli (Save the Children), Paulos Berglof (UN Women), Rachel Brown (Centre for Reproductive Rights), Antonio Cisneros (UNDG), Jarrod Clyne (Permanent Mission of New Zealand to the United Nations Office and other international organisations in Geneva), Jashodhara Dasgupta (SAHAYOG), Emilie Filmer-Wilson (UNDG), Stefan Germann (World Vision International), Cristina Gonzalez (Permanent Mission of the Eastern Republic of Uruguay to the United Nations Office and other international organisations in Geneva), Shyama Kuruvilla (WHO), Breda Lee (Permanent Mission of Ireland to the United Nations Office and other

international organisations in Geneva), Thiago Luchesi (Save the Children), Esther Major (Amnesty International), Ida Krogh Mikkelsen (UNFPA), Nicolette Moodie (UNICEF), Mitra Motlagh (UNICEF), Sandeep Prasad (Action Canada for Sexual Health and Rights), Sarah Rattray (UNDP), Neha Sood (Action Canada for Sexual Health and Rights), Marleen Temmerman (WHO), Jaime Todd-Gher (Amnesty International), and Rada Tzaneva (Amnesty International).

Contributors and sources: This article was the collaborative work of the human rights sub-work stream of the Global Strategy on Women's, Children's and Adolescents' Health, with major text contributed by all the authors. LG integrated feedback from the sub-work stream as well as various consultations with experts in the area of women's, children's, and adolescents' health and rights; she is the guarantor.

Competing interests: We have read and understood BMJ policy on declaration of interests and have no relevant interests to declare.

Provenance and peer review: Not commissioned; externally peer reviewed. 
The authors alone are responsible for the views expressed in this article, which does not necessarily represent the views, decisions, or policies of WHO or the institutions with which the authors are affiliated. Jyoti Sanghera chief ${ }^{1}$ Lynn Gentile human rights officer' Alfonso Barragues technical adviser on human rights ${ }^{3}$ Imma Guerras-Delgado child rights adviser ${ }^{1}$ Lucinda O'Hanlon women's rights adviser ${ }^{2}$ Rachel Louise Hinton technical officer ${ }^{4}$ Kumanan Rasanathan senior health specialist ${ }^{6}$ Marcus Stahlhofer adviser, child and adolescent rights ${ }^{7}$ Rajat Khosla human rights adviser ${ }^{5}$

${ }^{1}$ Human Rights and Economic and Social Issues Section, Office of the High Commissioner for Human Rights, United Nations, Geneva, Switzerland

2Women's Rights and Gender Section, Office of the High Commissioner for Human Rights, United Nations

3United Nations Population Fund, New York, USA

4Partnership for Maternal Newborn and Child Health, World Health Organization, Geneva, Switzerland

${ }^{5}$ Department of Reproductive Health and Research, World Health Organization

6United Nations Children's Fund, New York, USA

${ }^{7}$ Department of Maternal, Newborn, Child and Adolescent Health Cluster for Family, Women's and Children's Health, World Health Organization

On behalf of the Human Rights Subwork Stream of the Global Strategy for Women's, Children's and Adolescents' Health.

Correspondence to: J Sanghera jsanghera@ohchr.org

Additional material is published online only. To view please visit the journal online (http://dx.doi. org/10.1136/bmj.h4184)

(c) World Health Organization 2015. Licensee BMJ This is an open access article distributed under the terms of the Creative Commons AttributionNoncommercial IGO License (https://creativecommons org/licenses/by-nc/3.0/igo/), which permits use, distribution, and reproduction for non-commercia purposes in any medium, provided the original work is properly cited. In any reproduction of this article there should not be any suggestion that WHO or this article endorse any specific organisation or products. The use of the WHO logo is not permitted. This notice should be preserved along with the article's original URL.

1 Committee on Economic, Social and Cultural Rights

(CESCR). General comment No 14: the right to the

highest attainable standard of health. UN, 2000; para 12.
2 Office of the United Nations High Commissioner for Human Rights, World Health Organization. Technical guidance on the application of a human rights-based approach to the implementation of policies and programmes to reduce preventable maternal morbidity and mortality. UN, 2012; para 3 and 13.

3 Convention on the Rights of the Child: article 6 (www.ohchr.org/en/professionalinterest/pages/crc. aspx)

4 Office of the United Nations High Commissioner for Human Rights, World Health Organization. Technical guidance on the application of a human rights based approach to the implementation of policies and programmes to reduce and eliminate preventable mortality and morbidity of children under 5 years of age. UN, 2014; para 21.

5 United Nations Committee on the Rights of the Child. General comment No 7: implementing child rights in early childhood. UN, 2005; para 14.

6 United Nations Committee on the Rights of the Child. General comment No 15: the right of the child to the highest attainable standard of health. UN, 2013; para 12 and 19 .

7 United Nations Committee on the Rights of the Child. General comment No 14: the right of the child to have his or her best interests taken as a primary consideration. UN, 2013.

8 Every Woman Every Child Technical Content Workstream Working Group on Early Child Development. Effective interventions and strategies for improving early child development. 2015. www.everywomaneverychild.org/ images/08 ECD background_paper_for_Global Strategy_FINAL_2015-03-23.pdf.

9 United Nations Committee on the Rights of the Child. General comment No 7: implementing child rights in early childhood. UN, 2005; para 10.

10 World Health Organization. Adolescent pregnancy. www.who.int/maternal_child_adolescent/topics/ maternal/adolescent_pregnancy/en/.

11 Office of the United Nations High Commissioner for Human Rights, World Health Organization. Technical guidance on the application of a human rights-based approach to the implementation of policies and programmes to reduce preventable maternal morbidity and mortality. UN, 2012; para 30.

12 Office of the United Nations High Commissioner for Human Rights, World Health Organization. Technical guidance on the application of a human rights based approach to the implementation of policies and programmes to reduce and eliminate preventable mortality and morbidity of children under 5 years of age. UN, 2014: para 35

13 Office of the United Nations High Commissioner for Human Rights, World Health Organization. Technical guidance on the application of a human rights based approach to the implementation of policies and programmes to reduce and eliminate preventable mortality and morbidity of children under 5 years of age. UN, 2014; para 28 and 29.

14 International Covenant on Economic, Social and Cultural Rights: article 2(1) (www.ohchr.org/EN/ Professionallnterest/Pages/CESCR.aspx).
15 Office of the United Nations High Commissioner for Human Rights, World Health Organization. Technical guidance on the application of a human rights-based approach to the implementation of policies and programmes to reduce preventable maternal morbidity and mortality. UN, 2012; para 21.

16 Office of the United Nations High Commissioner for Human Rights, World Health Organization. Technical guidance on the application of a human rights-based approach to the implementation of policies and programmes to reduce preventable maternal morbidity and mortality. UN, 2012; para 26.

17 United Nations Committee on the Rights of the Child. General comment No 7: implementing child rights in early childhood. UN, 2005; para 22

18 Office of the United Nations High Commissioner for Human Rights, World Health Organization. Technical guidance on the application of a human rights-based approach to the implementation of policies and programmes to reduce preventable maternal morbidity and mortality. UN, 2012; para 26 and 38

19 Office of the United Nations High Commissioner for Human Rights, World Health Organization. Technical guidance on the application of a human rights-based approach to the implementation of policies and programmes to reduce preventable maternal morbidity and mortality. UN, 2012; para 48.

20 United Nations Committee on the Rights of the Child General comment No 7: implementing child rights in early childhood. UN, 2005; para 11

21 United Nations Committee on the Rights of the Child. General comment No 7: implementing child rights in early childhood. UN, 2005; para 21(a), 26, and 27 (b).

22 Every Woman, Every Child, Technical Content Workstream Working Group on Determinants. Socioeconomic, political and environmental determinants: draft working paper. 2015. www.everywomaneverychild.org/ images/10 EWEC 2 0 Determinants draft working paper version 24 March 2015.pdf.

23 Office of the United Nations High Commissione for Human Rights, World Health Organization. Technical guidance on the application of a human rights-based approach to the implementation of policies and programmes to reduce preventable maternal morbidity and mortality. UN, 2012; para 74 and 75

24 Commission on Information and Accountability for Women's and Children's Health. Keeping promises, measuring results: recommendation 7. WHO, 2011

25 Office of the United Nations High Commissioner for Human Rights, World Health Organization. Technical guidance on the application of a human rights based approach to the implementation of policies and programmes to reduce and eliminate preventable mortality and morbidity of children under 5 years of age. UN, 2014; para 64-67.

Cite this as: BMJ 2015;351:h4184 